\title{
ANALISA PENGUJIAN PERFORMANSI MESIN PENGERING GABAH DENGAN PENGADUK BEROTARI KAPASITAS 11 KG
}

\author{
Triswanto Ginting ${ }^{1}$. Tulus B sitorus ${ }^{2}$, Farel H. Napitupulu ${ }^{3}$, Taufiq B.,N ${ }^{4}$, Syahril Gultom ${ }^{5}$ \\ 1,2,3,4,5 Departemen Teknik Mesin Fakultas Teknik, Universitas Sumatera Utara \\ E-mail : triswanto_g@ymail.com
}

\begin{abstract}
ABSTRAK
Saat musim panen gabah yang jatuh pada waktu musim hujan dimana sinar matahari tidak setiap hari ada untuk menjemur gabah, petani sering mengalami kerugian. Gabah yang basah pada saat dipanen akan bertahan kurang lebih 2 hari, setelah itu akan rusak. Untuk mengatasi hal tersebut, dirancang mesin pengering gabah sederhana yang menggunakan bahan yang sederhana dan ada disekitar kita. Mesin ini sangat berguna pada waktu panen raya gabah yang bertepatan dengan musin hujan. Mesin ini menggunakan reaktor pembakaran sebagai sumber penghasil udara panas untuk mengeringkan gabah. Bentuk ruang/tempat gabah adalah drum, memiliki lubang saluran masukan udara panas dari reaktor pembakaran. pengujian pengeringan gabah yang dilakukan sebanyak $11 \mathrm{~kg}$. Cara kerja mesin yaitu gabah $11 \mathrm{~kg}$ disimpan dalam wadah, bahan bakar dimasukkan kedalam Reaktor pembakaran berupa arang kayu dan cangkang kemiri lalu dibakar hingga menjadi bara api, lalu udara dialirkan ke wadah pengering. Selama 9 jam pengeringan, gabah dengan berat $11 \mathrm{~kg}$ mengalami penyusutan berat menjadi $9,3 \mathrm{~kg}$. Setelah selesai pengeringan gabah dilakukan maka diketahui efisiensi mesin pengering gabah dengan tambahan alat pengaduk berotari ialah $84,54 \%$.
\end{abstract}

Kata kunci : Pengering gabah, reaktor pembakaran, gabah

\section{PENDAHULUAN}

Gabah dikenal dengan nama latin ORYZA SATIVA adalah famili dari rumput rumputan (GRAMINEAE) merupakan salah satu bahan makanan dari biji bijian tertua didunia yang dikonsumsi sebagian besar manusia didunia termasuk di Indonesia. Pengeringan gabah yang dilakukan oleh petani selama ini ialah pengeringan yang dilakukan dengan bantuan sinar matahari, hal ini sangat dipengaruhi oleh faktor cuaca bila saat musim penghujan maka para petani tidak bisa mengeringkan gabah dengan bantuan sinar matahari, sehingga proses pengeringan akan semakin lama. Gabah dengan kadar air tinggi jika diproses menjadi beras dapat menyebabkan beras yang dihasilkan rusak, busuk, berjamur dan berubah warna. Sedangkan gabah dengan kandungan air rendah jika ditangani akan menghasilkan banyak beras patah atau menir. Oleh karena itu, untuk mengurangi kehilangan pasca panen maka gabah yang akan diproses harus segera dikeringkan hingga mencapai kadar air 13-14\%.

Maka dibuatlah "Mesin Gasifikasi Sebagai Sumber Penghasil Panas Untuk Mengeringkan Gabah Tanpa Blower" oleh mahasiswa Teknik Mesin Sumatera Utara. Pada mesin pengering tersebut dikeringkan dengan wadah statis sehingga proses pengeringan dan penurunan kadar air sangat lama membutuhkan waktu 9 hari. Dan konsumsi bahan bakar untuk menghasilkan panas juga bertambah hal ini menyebabkan biaya operasional mesin tersebut juga akan bertambah.

Berawal dari kendala dan permasalahan yang dialami saat pengoperasian mesin gasifikasi sebagai sumber penghasil panas untuk mengeringkan gabah tanpa blower maka timbul ide dan gagasan dari penulis untuk memodifikasi mesin pengering tersebut " mesin pengering gabah dengan pengaduk berotari kapasitas $11 \mathrm{~kg}$ ", berfungsi untuk membolakbalikkan (mengaduk) gabah agar mempercepat proses penurunan kadar air [4]. 


\section{TINJAUAN PUSTAKA}

\section{Pengeringan}

Pengeringan pada dasarnya adalah proses pemindahan/pengeluaran kandungan air bahan hingga mencapai kandungan tertentu agar kecepatan kerusakan bahan dapat diperlambat. Pengeringan dapat dilakukan dengan penjemuran yang memanfaatkan sinar matahari atau dengan cara buatan. Pengeringan buatan di samping untuk mengatasi pengaruh cuaca, kelembaban yang tinggi sepanjang tahun juga dimaksudkan untuk meningkatkan mutu hasil pengeringan.

Tujuan pengeringan ialah menurun kan kadar air gabah sampai 13-14\% untuk penyimpanan panjang. Untuk menanggulangi kendala tersebut digunakan peralatan pengeringan buatan. Energi untuk proses pengeringan dapat diperoleh dari proses pembakaran, minyak, gas ataupun biomassa. Tetapi penggunaan sumber-sumber energi dapat menyebabkan biaya produksi menjadi meningkat. Pengeringan buatan adalah pengeringan dengan menggunakan alat pengering, dimana suhu, kelembaban udara, kecepatan pengaliran udara dan waktu pengeringan dapat diatur dan diawasi [2].

\section{Keuntungan dan kerugian penjemuran alami}

Keuntungan dan kerugian penjemuran dibandingkan dengan pengeringan buatan adalah sebagai berikut:

a. Penjemuran sangat tergantung pada cuaca, sehingga kontinuitas pengeringan tidak teratur, misalnya kalau turun hujan terpaksa pengeringan dihentikan. Demikian pula suhu, kelembaban udara dan kecepatan udara tidak dapat diatur, sehingga kecepatan pengeringan tidak seragam.

b. Mutu gabah kering hasil penjemuran umumnya lebih rendah daripada hasil pengeringan menggunakan alat. Hal ini disebabkan karena waktu pengeringan yang lama, keadaan pengeringan dan tidak dapat dijaga dan diawasi sehingga kemungkinan-kemungkinan terjadinya kerusakan selama penjemuran sangat besar.

c. Keuntungan proses penjemuran adalah biayanya rendah karena memerlukan biaya dan alat-alat yang lebih murah.

\section{METODE PENELITIAN}

\section{Tahap pengujian mesin pengering gabah}

Data yang dipergunakan dalam pengujian mesin pengering gabah meliputi :

a. Data primer, merupakan data yang diperoleh langsung dari pengukuran dan pembacaan pada alat ukur pada masing - masing pengujian.

b. Data sekunder, merupakan data yang diperoleh dari hasil penelitian karakteristik gabah dari berbagai sumber yang ada

Data yang diperoleh dari data primer dan data skunder diolah ke dalam rumus empiris, kemudian data dari pengujian pengeringan gabah dan perhitungan penurunan kadar air gabah disajikan dalam bentuk tabulasi dan grafik.

\section{Prosedur Pengujian}

Adapun prosedur pengujian yang dilakukan sebagai berikut:

a. Persiapan bahan dan peralatan yang diperlukan saat proses pengeringan.

b. Menimbang bahan bakar awal ditimbang masing- masing dengan berat $6 \mathrm{~kg}$.

c. Memasukkan bahan bakar kedalam ruang bakar. 
d. Penutupan ruang pembakaran Tutup ruang pembakaran ikat dengan baut lalu kunci dengan kunci yang tersedia.

e. Memasukan gabah ke drum pengering Masukkan gabah yang telah ditimbang kedalam drum pengering sebanyak $11 \mathrm{~kg}$.

f. Pengukuran temperatur drum pengering Ukur temperatur drum pengering beberapa menit setelah dilakukannya proses pengeringan.

g. Proses pengeringan gabah Tunggu proses pengeringan sesuai dengan prosedur yang telah dibuat, yaitu 1 jam lamanya

h. Pengeluaran gabah Setelah satu jam lamanya proses pengeringan, keluarkan gabah dari saluran keluar, putar tuas pemutar untuk menggerakkan alat pemutar dalam drum pengering sehingga memudahkan proses pengeluaran gabah yang telah dikeringkan.

i. Penimbangan gabah Timbang berat gabah yang telah dikeringkan dengan menggunakan timbangan yang telah tersedia, catat berat gabah yang telah dikeringkan sehingga diperoleh pengurangan berat gabah.

j. Pemasukan gabah kembali Masukkan kembali gabah yang telah ditimbang kedalam drum pengering untuk proses pengeringan selanjutnya, tunggu hingga 1 jam kemudian dan timbang kembali berat gabah yang telah dikeringkan,lakukan secara berulang ulang.

k. Selesai.

\section{Rumus-rumus Yang Digunakan}

1.Menghitung penurunan kadar air gabah:

Kadar air $(\%)=\frac{\text { Massa gabah setelah pengeringan }}{\text { Massa padi sebelum pengeringan }} \times 100 \%$ [1].

2.Laju pengeringan

Laju pengeringan $=\frac{d w}{d t}=\frac{w o-w f}{\Delta t}[1]$.

3.Efisiensi Pengeringan

Efesiensi pengeringan dihitung dengan cara :

$$
\varepsilon=\frac{\text { gabah kering }}{\text { Gabah basah }} X 100 \% \text { [1]. }
$$

Dimana :

$\mathrm{dw} / \mathrm{dt}=$ Laju pengeringan [ \%/jam ]

$$
\begin{array}{ll}
\text { wo } & =\text { Kadar air awal [\%] } \\
\text { wf } & =\text { Kadar air akhir [\%] } \\
\Delta \mathrm{t} & =\text { Selang waktu [jam] }
\end{array}
$$

\section{HASIL DAN PEMBAHASAN}

Setelah dilakukan analisa dari percobaan yang dilakukan maka Data yang diperoleh melalui pengujian mesin pengering gabah disajikan dalam tabel berikut

Tabel : Pengujian pengeringan gabah $11 \mathrm{~kg}$

\begin{tabular}{|l|l|}
\hline Tanggal pengujian & $\begin{array}{l}\text { 20 Desember 2014 } \\
\text { hingga selesai }\end{array}$ \\
\hline Bahan Bakar & $\begin{array}{l}\text { Arang dan Cangkang } \\
\text { Kemiri }\end{array}$ \\
\hline
\end{tabular}




\begin{tabular}{|c|c|c|c|c|c|c|}
\hline \multicolumn{3}{|c|}{$\begin{array}{l}\text { Total Massa Bahan } \\
\text { Bakar }\end{array}$} & \multicolumn{4}{|c|}{$24[\mathrm{~kg}]$} \\
\hline \multicolumn{3}{|c|}{ Massa Gabah } & \multicolumn{4}{|c|}{11 [kg] } \\
\hline \multicolumn{3}{|c|}{ Waktu pembakaran } & \multicolumn{4}{|c|}{12 [jam] } \\
\hline \multicolumn{3}{|c|}{ Waktu pengeringan } & \multicolumn{4}{|c|}{9 [jam] } \\
\hline $\begin{array}{c}\text { Wakt } \\
\text { u } \\
{[\text { WIB }} \\
\text { ] }\end{array}$ & $\begin{array}{c}\text { Mas } \\
\text { sa } \\
\text { gab } \\
\text { ah } \\
{[\mathrm{kg}]}\end{array}$ & $\begin{array}{c}\text { Suh } \\
\text { u } \\
\text { dru } \\
\text { m } \\
{\left[{ }^{\circ} \mathrm{C}\right]}\end{array}$ & $\begin{array}{l}\text { Sele } \\
\text { sai } \\
{[W I} \\
\text { B] }\end{array}$ & $\begin{array}{c}\text { Setela } \\
\mathbf{h} \\
\text { penge } \\
\text { ringa } \\
\mathbf{n} \\
{[\mathrm{kg}]}\end{array}$ & $\begin{array}{c}\text { Selis } \\
\text { ih } \\
\text { bera } \\
\text { t } \\
\text { gab } \\
\text { ah }\end{array}$ & $\begin{array}{c}\text { Ha } \\
\text { ri } \\
\text { pe } \\
\text { ng } \\
\text { uji } \\
\text { an }\end{array}$ \\
\hline 13.00 & 11 & 36 & $\begin{array}{c}14.0 \\
0\end{array}$ & 11 & 0 & I \\
\hline 14.20 & 11 & 40 & $\begin{array}{c}15.2 \\
0\end{array}$ & 10,75 & 0,25 & I \\
\hline 15.40 & $\begin{array}{c}10,7 \\
5\end{array}$ & 45 & $\begin{array}{c}16.4 \\
0\end{array}$ & 10,60 & 0,15 & $\mathrm{I}$ \\
\hline 17.00 & $\begin{array}{c}10,6 \\
0\end{array}$ & 45 & $\begin{array}{c}18.0 \\
0\end{array}$ & 10 & 0,60 & $\mathrm{I}$ \\
\hline 18.20 & 10 & 45 & $\begin{array}{c}19.2 \\
0\end{array}$ & 9,45 & 0,55 & I \\
\hline 19.40 & 9,45 & 45 & $\begin{array}{c}20.4 \\
0\end{array}$ & 9,30 & 0,15 & I \\
\hline 21.00 & 9,30 & 45 & $\begin{array}{c}22.0 \\
0\end{array}$ & 9.30 & 0 & $\mathrm{I}$ \\
\hline 22.00 & & & SEL & SAI & & \\
\hline Hasil & 11 & 45 & $\begin{array}{c}22.0 \\
0\end{array}$ & 9,3 & 1,7 & $\mathbf{I}$ \\
\hline
\end{tabular}

Gambar grafik penyusutan berat gabah setelah dimodifikasi 


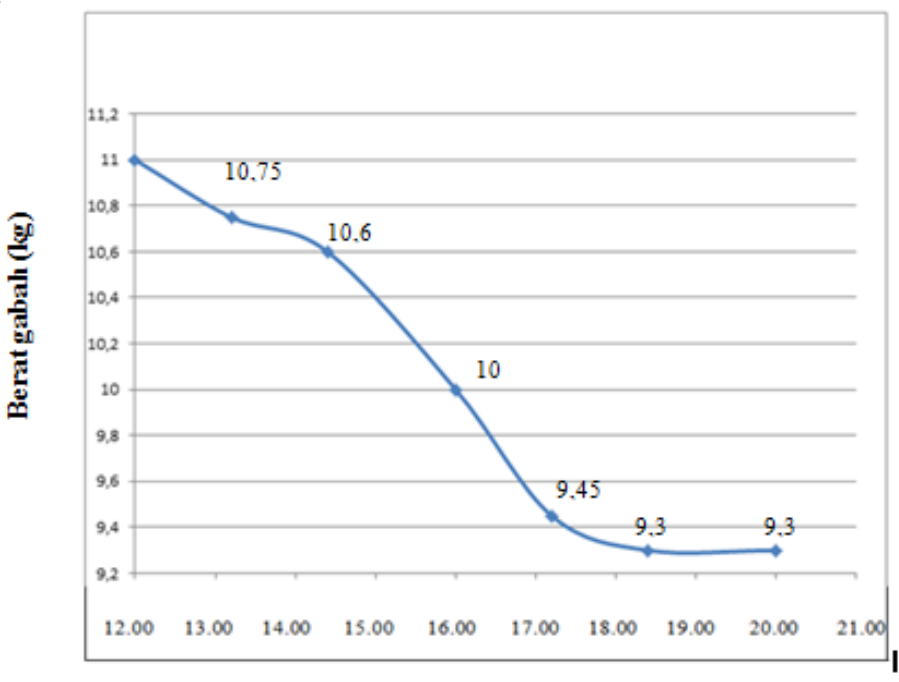

Waktu nengeringan (bukul)

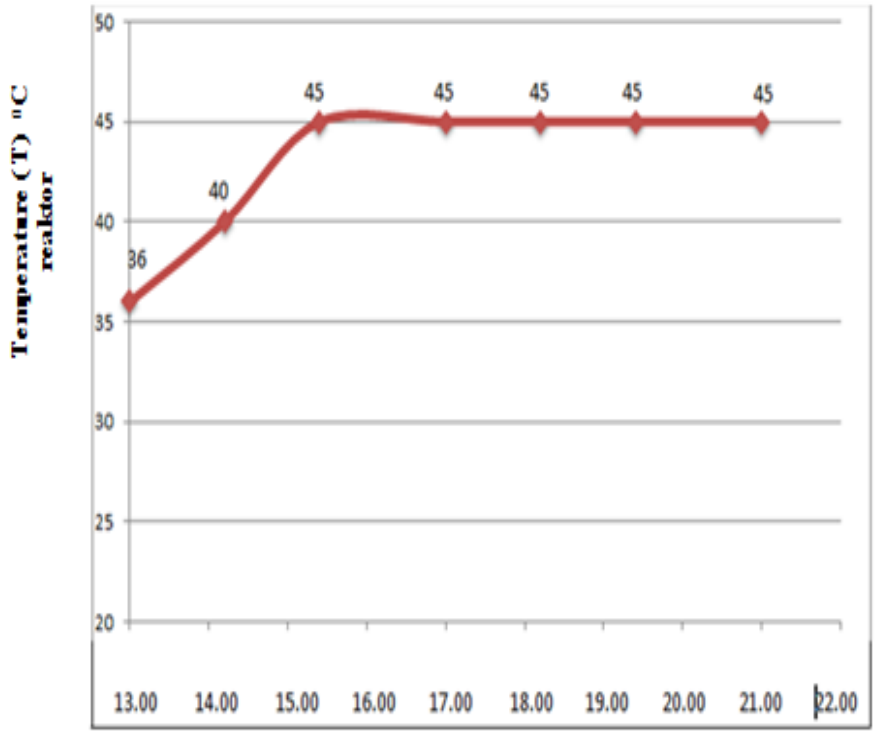

$$
\begin{gathered}
\varepsilon=\frac{\text { gabah kering }}{\text { Gabah basah }} \times 100 \% \\
\varepsilon=\frac{9,3 \mathrm{~kg}}{11} \times 100 \% \\
\varepsilon=84,54 \%
\end{gathered}
$$

Jadi efesiensi pengeringan gabah ialah $84,54 \%$

\section{KESIMPULAN}

Setelah penulis melakukan perhitungan dan uji coba pada mesin pengering buatan yaitu mesin pengering gabah dengan pengaduk, maka dapat disimpulkan sebagai berikut :

1. Temperatur drum pengering menggunakan bahan bakar arang dan cangkang kemiri yaitu $45^{0} \mathrm{C}$. 
2. Proses pengeringan selama 9 jam jumlah bahan bakar yang digunakan ialah $24 \mathrm{~kg}$, dengan sisa pembakaran bahan bakar seberat $\pm 3 \mathrm{~kg}$.

3. Bahan bakar lebih hemat karena cangkang kemiri menghasilkan panas yang lebih tahan lama.

4. Waktu yang dibutuhkan selama proses pengeringan menjadi lebih singkat, dibandingkan dengan mesin pengering sebelumnya, karena adanya penambahan jumlah lubang dan diameter lubang menuju pipa saluran udara panas pada reaktor dalam sehingga panas yang tersalur kedalam drum pengering menjadi lebih besar.

5. Panas hasil pembakaran lebih cepat memanaskan ruang drum pengering hingga mencapai temperatur yang tetap yaitu $45^{\circ} \mathrm{C}$. Karena jarak pipa saluran udara panas menuju drum pengering telah diperpendek.

6. Gabah dengan berat $11 \mathrm{~kg}$ setelah dilakukan proses pengeringan membutuhkan waktu selama 9 jam lamanya, massa gabah berkurang menjadi 9,3 kg. Dengan hasil pengurangan kadar air gabah sebanyak $17 \%$. Dan pengurangan massa gabah ialah 1,7 $\mathrm{kg}$.

7. Dibandingkan dengan mesin pengering sebelumnya, mesin pengering gabah dengan alat pengaduk ini lebih effesien dan menghemat waktu, dimana pengeringan sebelumnya membutuhkan waktu 65 jam 30 menit, untuk mengeringkan gabah $10 \mathrm{~kg}$ dengan penurunan kadar air 15,69 \%, sementara mesin pengering gabah dengan pengaduk berotari hanya 9 jam dengan mengeringkan gabah $11 \mathrm{~kg}$ hasil pengurangan kadar air gabah sebanyak $17 \%$ dan pengurangan massa gabah ialah $1,7 \mathrm{~kg}$.

\section{Saran}

1. Perlu dilakukan pemodifikasian pada ruang bakar untuk pembuangan sisa pembakaran.

2. Perlu dilakukan pembuatan corong masuk untuk memudahkan dalam memasukkan gabah kedalam drum pengering

3. Pipa saluran udara panas dari ruang bakar menuju drum pengering sebaiknya diperpendek lagi agar hasil panas pembakaran lebih cepat masuk kedalam drum pengering.

4. Gunakan puli bertingkat yang menggunakan 2 sabuk bila ingin mengeringkan gabah dengan kapasitas yang lebih besar, atau transmisi rantai agar saat melakukan pengadukan tidak terjadi slip saat memutar beban gabah yang lebih besar pada pengaduk.

5. Bagi mahasiswa yang nantinya akan merevisi alat ini diharapkan bisa merancang alat pengering gabah dengan proses pengeringan yang lebih baik.

\section{DAFTAR PUSTAKA}

[1] D.H.Bacon, B.Sc.,R.C. Stephencus, 1982. Thermodinamics For Thechnician. TEC Butter Worth.

[2] Gunarif taib, dkk. 1988. Operasi pengeringan pada pengolahan hasil pertanian. Jakarta. Msp

[3] Holman. J.P. 1995. Perpindahan kalor. Diterjemahkan Jafisi,E. Jakarta. Erlangga.

[4] Kartasapoetra. 1994. Teknologi penyuluhan pertanian. Jakarta . Bina aksara.

[5] Sularso, kiyokatsu suga. 1978. Dasar perencanaan dan pemilihan elemen mesin. Jakarta. PT Pradnya Paramita.

[6] Winarno, dkk. 1997. Pengantar teknologi Pangan. PT. Jakarta. Gramedia. 